\title{
Penguatan Pendidikan Karakter Berbasis Sekolah Menengah Atas (SMA) Perbatasan Entikong Kalimantan Barat
}

\author{
Thomy Sastra Atmaja ${ }^{1}$, Jagad Aditya Dewantara ${ }^{2}$, Bambang Budi Utomo ${ }^{3}$ \\ Universitas Tanjungpura, Kalimantan Barat, Indonesia ${ }^{1,2,3}$ \\ E-mail : thomy.sastra@ fkip.untan.ac.id ${ }^{1}$ jagad02@ fkip.untan.ac.id ${ }^{2}$ bambangbudiutomo56@ gmail.com $^{3}$
}

\begin{abstract}
Abstrak
Entikong marupakan salah satu wilayah perbatasan Indonesia dan Malaysia menyimpan potensi degradasi nilai karakter bangsa yang cukup besar. Menyikapi hal tersebut, maka lembaga pendidikan (sekolah) di perbatasan Entikong menerapkan program penguatan pendidikan karakter sebagai instrumen preventif dalam membina dan menumbuh kembangkan nilai utama karakter bangsa (religius, nasionalis, mandiri, gotong royong, integritas). Penelitian ini bertujuan untuk mengetahui implementasi penguatan pendidikan karakter berbasis sekolah di SMA Perbatasan Entikong Kalimantan Barat. Penelitian menggunakan metode deskriptif dengan pendekatan kualitatif. Hasil penelitian menunjukkan bahwa penguatan pendidikan karakter berbasis sekolah di SMA Perbatasan Entikong Kalbar dilakukan melalui 3 (tiga) program yakni (1) Penguatan pendidikan karakter melalui program pengembangan diri, (2) penguatan pendidikan karakter melalui integrasi dalam mata pelajaran, dan (3) penguatan pendidikan karakter melalui budaya sekolah.
\end{abstract}

Kata kunci: pendidikan karakter, berbasis sekolah

\section{Abstract}

Entikong is one of the border areas between Indonesia and Malaysia which has a significant degradation potential for the character value of the nation. Responding to this, educational institutions (schools) at the Entikong border implement a character education strengthening program as a preventive instrument in fostering and developing the main values of the nation's character (religious, nationalist, independent, mutual cooperation, integrity). This study aims to determine the implementation of strengthening school-based character education in SMA Border Entikong, West Kalimantan. This research uses descriptive method with a qualitative approach. The results showed that the strengthening of school-based character education in SMA Border Entikong West Kalimantan was carried out through 3 (three) programs namely (1) self-development, integrating in subjects, and through school culture.

Keywords: character education, school based

Copyright (c) 2020 Thomy Sastra Atmaja, Jagad Aditya Dewantara, Bambang Budi Utomo

$\triangle$ Corresponding author

Address : Jalan Prof. Dr. H. Hadari Nawawi, Pontianak 78124

Email : Jagad02@fkip.untan.ac.id

ISSN 2580-3735 (Media Cetak)

Phone : : 089681943104

ISSN 2580-1147 (Media Online)

DOI: https://doi.org/10.31004/basicedu.v4i4.545 
1258 Penguatan Pendidikan Karakter Berbasis Sekolah Menengah Atas (SMA) Perbatasan Entikong Kalimantan Barat - Thomy Sastra Atmaja, Jagad Aditya Dewantara, Bambang Budi Utomo DOI: https://doi.org/10.31004/basicedu.v4i4.545

\section{PENDAHULUAN}

Perhatian pemerintah terhadap upaya pengembangan karakter bangsa secara lebih serius disikapi mulai tahun 2010. Keseriusan pemerintah tersebut ditandai dengan dirumuskannya naskah Pedoman Pendidikan Budaya dan Karakter Bangsa yang dikeluarkan bersama oleh Badan Penelitian dan Pengembangan dengan beberapa unit utama di lingkungan Kementerian Pendidikan Nasional serta kantor Menteri Koordinator Kesejahteraan Rakyat. Tujuan dirumuskannya naskah Pedoman Pendidikan Budaya dan Karakter Bangsa tersebut yakni sebagai rujukan praktis bagi para pendidik dan peminat pendidikan dalam melaksanakan program pendidikan berbasis karakter baik di kelas maupun di sekolah.

Perhatian dan keseriusan pemerintah terhadap upaya pengembangan karakter bangsa juga tampak jelas pada nawacita bidang pendidikan pemerintahan presiden Jokowidodo dan Jusuf Kalla tahun 2014. Dalam nawacita terkait pendidikan disebutkan bahwa pemerintah berkomitmen untuk "melakukan revolusi karakter bangsa" (Safitri, 2015). Menyikapi nawacita tersebut Presiden Jokowidodo juga menegaskan bahwa saat ini pondasi pendidikan sesungguhnya terletak pada pendidikan karakter itu sendiri yang dapat ditanamkan sejak jenjang sekolah dasar hingga pendidikan tinggi. Pada saat bersamaan Presiden (pemerintah) juga mengeluarkan Peraturan Presiden Republik Indonesia Nomor 87 Tahun 2017 tentang Penguatan Pendidikan Karakter (PPK) sekaligus mengeluarkan Buku Pedoman Penguatan Pendidikan Karakter yang dikeluarkan oleh Pusat Analisis dan Sinkronisasi Kementerian Pendidikan dan Kebudayaan Tahun 2017 (Peraturan Presiden Republik Indonesia Nomor 87, 2017).
Kecenderungan pemerintah mengembangkan karakter bangsa sebagaimana di atas bukan tanpa alasan jika kita kaitkan dengan berbagai prilaku menyimpang yang dilakukan oleh anak usia sekolah akhir-akhir ini. Sikap dan prilaku agresif yang amoral dan jauh dari nilai luhur karakter bangsa semakin hari kian meresahkan dan terjadi disekitar kita. Sebagai contoh kasus tawuran antar pelajar, berkelahi dengan teman, pemakaian obat-obatan terlarang, balap liar, mengonsumsi minuman keras dan beberapa prilaku menyimpang lainnya. Bahkan kasus yang pernah terjadi yang menyita perhatian dan mengagetkan dunia pendidikan di Kalimantan Barat yakni kasus perundungan atau pengeroyokan siswi SMP atas nama Audrey oleh beberapa siswi SMA di Kota Pontianak yang berujung pada pelecehan seksual (Flora, 2019). Kemudian belum genap satu bulan kasus Audrey, terjadi kembali kasus murid salah satu SMP di Kecamatan Pontianak Timur memukul guru dengan kursi karena tidak terima ditegur guru saat bermain ponsel pada saat jam pelajaran berlangsung yang mengakibatkan sang guru Nuzul Kurniawati, S.Pd harus masuk rumah sakit (Suroso, 2018). Dari beberapa contoh kasus di atas maka sebagai pelaku pendidikan atau pemerhati pendidikan tentu kasus tersebut harus dijadikan sebagai bahan refleksi diri untuk meningkatkan pengelolaan pendidikan di sekolah yang lebih berorientasi pada pengembangan nilai karakter bangsa.

Persoalan budaya dan karakter bangsa memang menjadi sorotan tajam masyarakat sehingga seringkali menjadi bahan perdebatan dan dialog di berbagai kesempatan. Para ahli, pengamat sosial, maupun pengamat pendidikan seringkali 
1259 Penguatan Pendidikan Karakter Berbasis Sekolah Menengah Atas (SMA) Perbatasan Entikong Kalimantan Barat - Thomy Sastra Atmaja, Jagad Aditya Dewantara, Bambang Budi Utomo

DOI: https://doi.org/10.31004/basicedu.v4i4.545

membicarakan mengenai persoalan budaya dan karakter bangsa di berbagai forum dan seminar baik tingkat lokal, nasional, maupun internasional. Berbagai alternatif penyelesaian masalah budaya dan karakter bangsa diajukan beragam oleh beberapa kalangan. Imbasnya lembaga pendidikan (sekolah) dipilih menjadi salah satu alternatif yang bersifat preventif untuk menyelesaikan masalah tersebut (Dewantara et al., 2020).

Sejauh ini pendidikan dipandang mampu membangun peradaban dan generasi bangsa kearah yang lebih baik. Oleh karena itu pendidikan tidak boleh mengalami kegagalan dalam mengembangkan karakter anak bangsa. Pendidikan di sekolah pada hakikatnya tidak sebatas membekali anak didik dengan sejumlah pengetahuan yang bersifat kognitif dan psikomotor belaka, akan tetapi jauh lebih penting pendidikan dan pembelajaran harus mampu membekali anak didik dengan seperangkat karakter bangsa sehingga akan terbentuk harmonisasi antara olah hati (etik), olah rasa (estetik), olah pikir (literasi), dan olah raga (kinestetik).

Berdasarkan peta jalan gerakan PPK yang digulirkan pemerintah, pada tahun 2016 mulai diujicobakan secara bertahap di 542 sekolah. Kemudian dilanjutkan tahun 2017 berjumlah 61.507 sekolah di 34 propinsi di Indonesia. Setelah proses ujicoba dan pematangan konsep tersebut, mamasuki tahun 2018 dan 2019 pemerintah menetapkan untuk mengimplementasikan secara mandiri dan bertahap serta melakukan pemantauan dan evaluasi pelaksanaan program PPK tersebut. Barulah pada tahun 2020 pemerintah menetapkan implementasi penuh dan mandiri program PPK serta menjadikan program unggulan bagi setiap sekolah dalam mengembangkan karakter peserta didik (Kementerian Pendidikan dan Kebudayaan, n.d.). Dengan demikian sebagai konsekuensi dari penetapan tersebut, maka sekolah di seluruh wilayah Indonesia (termasuk di daerah tertinggal, terdepan, dan terluar) saat ini telah mencoba melaksanakan program PPK tersebut sesuai dengan karakteristik dan kondisi yang ada di satuan pendidikan masingmasing.

Sekolah yang berada di daerah perbatasan Entikong Kalimantan Barat telah melaksanakan berbagai upaya pengembangkan karakter peserta didik. Meskipun memang pelaksanaannya belum dalam bingkai PPK yang seutuhnya namun secara prinsip pengembangan karakter yang dilakukan telah merupakan bagian dari program PPK. Seperti penelitian yang dilakukan oleh Yustiani tahun 2018 berjudul "nasionalisme melalui pendidikan di sekolah pada siswa di wilayah perbatasan Kalimantan Barat". Temuan penelitian mengungkapkan bahwa penanaman nilai-nilai nasionalisme di SMA Negeri 1 Sekayam Entikong telah dilakukan melalui integrasi pada mata pelajaran Pendidikan Agama, integrasi melalui kegiatan ektrakurikuler dan melalui budaya sekolah. Dari hasil penelitian tersebut turut mempertegas bahwa pengembangan karakter telah dilakukan di sekolah perbatasan Entikong. Saat ini pengembangan karakter peserta didik dilakukan oleh sekolah melalui kegiatan rutin seperti melaksanakan upacara bendera, mengarahkan peserta didik melaksanakan ibadah di sekolah, membersihkan lingkungan sekolah, serta kegiatan lainnya maupun melalui berbagai kegiatan spontan, pengondisian, dan keteladanan (Yustiani, 2018). 
1260 Penguatan Pendidikan Karakter Berbasis Sekolah Menengah Atas (SMA) Perbatasan Entikong Kalimantan Barat - Thomy Sastra Atmaja, Jagad Aditya Dewantara, Bambang Budi Utomo DOI: https://doi.org/10.31004/basicedu.v4i4.545

Atas dasar kondisi tersebut di atas, maka pengembangan karakter melalui program PPK yang dilakukan oleh sekolah di perbatasan Entikong menarik untuk dilakukan penelitian. Penelitian ini mengkaji dari sudut pandang yang berbeda. Dalam beberapa penelitian yang pernah dilakukan sebelumnya, banyak penelitian yang lingkup kajiannya melihat nilai karakter masyarakat perbatasan pada umumnya. Seperti penelitian yang dilakukan oleh M. Ishaq tahun 2011 dengan judul "pembinaan nasionalisme pemuda perbatasan melalui program pendidikan luar sekolah". Hasil penelitian menyebutkan bahwa masyarakat di daerah perbatasan Entikong mengalami krisis nasionalisme, dan program pendidikan luar sekolah bisa berjalan efektif jika para pendidik membimbing warga belajar sebagai kader penerus perjuangan bangsa (Ishaq, 2011). Kemudian penelitian lain yang dilakukan oleh Mardawani dan Agusta Kurniati tahun 2017 dengan judul "model pembinaan rasa kebangsaan melalui citizenship education pada masyarakat Entikong wilayah perbatasan Indonesia-Malaysia". Hasil penelitian menunjukkan bahwa model pembinaan rasa kebangsaan melalui citizenship education pada masyarakat Entikong wilayah perbatasan IndonesiaMalaysia adalah model persuasif dengan mengajak masyarakat berpartisipasi aktif mensukseskan program pemerintah (Mardawani \& Kurniati, 2017). Dari kedua penelitian terdahulu di atas, dapat dipertegas bahwa posisi penelitian yang akan di lakukan ini berbeda dari penelitian sebelumnya. Karena penelitian ini ingin melihat upaya pengembangan karakter melalui program PPK yang dilakukan di sekolah perbatasan Entikong Kalimantan Barat.
Sebagaimana kita ketahui bersama bahwa masyarakat perbatasan Entikong merupakan individu yang mengalami proses akulturasi dan asimilasi budaya lokal dan budaya luar. Untuk meminimalisir terjadinya hal tersebut, maka pengembangan karakter peserta didik di sekolah perbatasan Entikong merupakan upaya yang harus dilakukan secara terprogram. Pentingnya program PPK di sekolah perbatasan bertujuan untuk membentuk manusia Indonesia yang berbudaya dan berkarakter Pancasila yang ditandai dengan kepemilikan nilai-nilai utama karakter bangsa seperti religius, nasionalis, mandiri, gotong royong dan integritas (Prasetiyo et al., 2019; Tim Pendidikan Karakter, 2010).

Berangkat dari semua fakta dan pemaparan di atas, maka penelitian dengan judul "Implementasi Penguatan Pendidikan Karakter Berbasis Sekolah di SMA Perbatasan Entikong Kalimantan Barat “ menarik untuk dilakukan penelitian lebih lanjut.

\section{METODE}

Rancangan penelitian; Penelitian ini ingin menjawab pola implementasi penguatan pendidikan karakter berbasis sekolah di SMA Perbatasan Entikong Kalimantan Barat. Metode penelitian deskriptif dengan pendekatan penelitian kualitatif.

Prosedur penelitian melalui 4 (empat) tahapan. (1) Tahap pengumpulan data; kegiatan yang dilakukan adalah mengumpulkan fakta-fakta yang ditemukan di situs penelitian yang terkait dengan aspek penelitian. (2) Tahap reduksi data, kegiatan yang dilakukan menelaah kembali terhadap seluruh laporan dan catatan hasil penelitian yang diperoleh di lapangan. (3) Tahap penyajian data, yakni peneliti melakukan penyajian secara sistematis dalam bentuk 
1261 Penguatan Pendidikan Karakter Berbasis Sekolah Menengah Atas (SMA) Perbatasan Entikong Kalimantan Barat - Thomy Sastra Atmaja, Jagad Aditya Dewantara, Bambang Budi Utomo DOI: https://doi.org/10.31004/basicedu.v4i4.545

teks atau narasi sesuai dengan aspek-aspek penelitian. (4) Penarikan kesimpulan atau verifikasi, yakni peneliti mencari pola, tema, hubungan, persamaan dan lain sebagainya untuk kemudian diambil suatu kesimpulan akhir untuk mengungkap temuan-temuan penelitian (Creswell, 2010).

Obyek penelitian; yang menjadi obyek/sasaran dalam penelitian ini adalah penerapan program penguatan pendidikan karakter (PPK) yang dilakukan oleh Sekolah Menengah Atas (SMA) di Perbatasan Entikong Kalimantan Barat. SMA yang diteliti berjumlah 4 yakni SMAN 1 Sekayam, SMAN 2 Sekayam, SMKN 1 Entikong dan SMAN 1 Beduai.

Partisipan penelitian; karakteristik partisipan dalam penelitian yaitu: (1) pelaku pendidikan (Kepala Sekolah, dan Guru) yang bertugas di SMA Perbatasan Entikong Kalimantan Barat, (2) pada saat penelitian dilakukan masih berstatus pegawai aktif, (3) partisipan mengetahui atau sebagai pengambil kebijakan di sekolah. Jumlah partisipan seluruhnya yakni 4 Kelapa Sekolah dan 2 Guru.

Instrumen penelitian; yang menjadi instrumen utama dalam penelitian ini adalah peneliti sendiri (human instrument) dengan bantuan pedoman wawancara dan observasi. Didalam menghadapi karakteristik penelitian kualitatif yang segala sesuatunya belum mempunyai bentuk yang pasti atau senantiasa berkembang sepanjang penelitian berlangsung, maka yang bertindak sebagai instrumen penelitian adalah peneliti sendiri (human instrument) agar dapat mengungkap fakta-fakta di situs penelitian (Arikunto, 1998; Sugiyono, 2011).

Teknik analisis data; analisis data di lapangan peneliti lakukan melalui tahap pengumpulan data, reduksi data, sajian data, dan penarikan kesimpulan/verifikasi (Moleong, 2007; Satori \& Komariah, 2011). Miles dan Huberman (1992) mengemukakan bahwa dalam penelitian kualitatif aktivitas dalam analisis data meliputi data reduction, data display, dan conclusion drawing/verification” (Miles \& Huberman, 1992).

\section{HASIL DAN PEMBAHASAN}

\section{Penguatan Pendidikan Karakter melalui Program Pengembangan Diri di SMA Perbatasan Entikong Kalimantan Barat.}

Penguatan pendidikan karakter melalui program pengembangan diri di Sekolah Menengah Atas (SMA) Perbatasan Entikong Kalimantan Barat dilakukan melalui kegiatan rutin, kegiatan spontan, kegiatan keteladanan dan kegiatan pengondisian. Kegiatan rutin seperti upacara bendera pada hari senin, bersalaman antara murid dengan guru di pintu gerbang sekolah atau sebelum masuk ruang kelas, mengucapkan salam ketika masuk ruang kelas, berdoa sebelum dan setelah pembelajaran, kegiatan literasi membaca selama 30 menit sebelum pembelajaran dimulai, piket membersihkan ruang kelas oleh peserta didik secara bergantian, melaksanakan ibadah (sholat dzuhur) secara berjamaah, dan setiap tahun sekolah mendukung pelaksanaan kegiatan keagamaan. Selanjutnya kegiatan spontan yang dilakukan oleh sekolah dalam rangka pengembangan karakter peserta didik yakni menindak tegas dengan sanksi jika ada peserta didik yang melanggar disiplin atau tata tertib (terlambat tiba disekolah, berkelahi, berpakaian tidak rapi, buang sampah sembarangan, berkata kasar), melakukan penggalangan dana jika terdapat salah satu warga sekolah yang tertimpa musibah, 
1262 Penguatan Pendidikan Karakter Berbasis Sekolah Menengah Atas (SMA) Perbatasan Entikong Kalimantan Barat - Thomy Sastra Atmaja, Jagad Aditya Dewantara, Bambang Budi Utomo DOI: https://doi.org/10.31004/basicedu.v4i4.545

mengunjungi warga sekolah yang sakit atau adanya kematian. Kemudian kegiatan keteladanan yang dilakukan oleh sekolah yakni semua warga sekolah wajib menunjukkan contoh teladan yang baik seperti berpakaian yang rapi, berkarakter dalam sikap, tindakan dan perbuatan. Dan terakhir kegiatan pengondisian dilakukan melalui penataan ruang kelas, ruang guru, ruang kepala sekolah, ruang perpustakaan dan seluruh ruangan di sekolah secara rapi dan bersih, lingkungan serta halaman sekolah bersih dan rapi, taman dan lingkungan sekolah yang hijau dan terawat, tersebar banyak tong sampah di lingkungan sekolah, lingkungan sekolah bersih dari sampah, serta kondisi toilet yang bersih, terawat, dan dengan jumlah yang cukup (Tim Penguatan Pendidikan Karakter, 2012).

Dalam kaitannya dengan penguatan pendidikan karakter Samani menyatakan bahwa penguatan pendidikan karakter melalui program pengembangan diri di sekolah dapat dilakukan melalui empal kegiatan yakni: kegiatan rutin, spontan, keteladanan, dan pengondisian (Samani \& Hariyanto, 2013).

\section{Penguatan Pendidikan Karakter Melalui Integrasi dalam Mata Pelajaran di SMA Perbatasan Entikong Kalimantan Barat}

Pengembangan/penguatan pendidikan karakter di Sekolah Menengah Atas (SMA) Perbatasan Entikong Kalimantan Barat dilakukan melalui integrasi/menyisipkan nilai karakter bangsa kedalam setiap pokok bahasan dari setiap mata pelajaran. Upaya ini dilakukan oleh guru mulai dari penyusunan Rencana Pelaksanaan Pembelajaran, tahap pelaksanaan proses pembelajaran, hingga penilaian pembelajaran (aspek afektif).

Kenyataan tersebut sejalan dengan Pedoman pendidikan karakter yang dikeluarkan oleh Kementerian Pendidikan dan Kebudayaan (2012) mengariskan bahwa penguatan Pendidikan Karakter berbasis kelas dapat dilakukan melalui integrasi isi kurikulum dalam mata pelajaran, baik itu secara tematik maupun terintegrasi dalam mata pelajaran (Tim Penguatan Pendidikan Karakter, 2017).

\section{Penguatan Pendidikan Karakter Melalui Budaya Sekolah di SMA Perbatasan Entikong Kalimantan Barat}

Pengembangan/penguatan pendidikan karakter melalui budaya sekolah di Sekolah Menengah Atas (SMA) Perbatasan Entikong Kalimantan Barat dilakukan dengan cara menetapkan visi dan motto sekolah yang mengandung nilai karakter, memajang banyak bendera merah putih di sepanjang teras sekolah untuk menumbuhkan rasa nasionalisme dan patriotisme, memajang banyak kalimat motivasi dan bernilai karakter di sepanjang lingkungan sekolah, menerapkan 5S yakni (senyum, salam, sapa, sopan, santun) kepada seluruh warga sekolah, menampilkan sikap saling peduli dan kasih sayang kepada seluruh warga sekolah, menetapkan tata tertib sebagai rujukan tingkah laku seluruh warga sekolah, menciptakan program unggulan sekolah (berupa setiap pagi peserta didik dikumpulkan dilapangan untuk menyanyikan lagu-lagu kebangsaan/nasionalis serta bersalaman kepada seluruh dewan guru, ada pula program unggulan berupa menyanyikan lagu kebangsaan Indonesia Raya saat memulai pembelajaran dan menyanyikan lagu 
1263 Penguatan Pendidikan Karakter Berbasis Sekolah Menengah Atas (SMA) Perbatasan Entikong Kalimantan Barat - Thomy Sastra Atmaja, Jagad Aditya Dewantara, Bambang Budi Utomo

DOI: https://doi.org/10.31004/basicedu.v4i4.545

nasional/kebangsaan saat akan pulang, bahkan ada pula program unggulan berupa kegiatan Pendidikan Bela Negara pada organisasi Osis dan kegiatan Masa Orientasi Sekolah (MOS) selama 3 hari yang dilatih dari Anggota TNI maupun POLRI), melaksanakan kegiatan ekstakurikuler yang dapat membentuk karakter peserta didik seperti (OSIS, Paskibra, Pramuka, PMR, Rohis, Pendalaman Iman, Silat, Karate, Taekwondo, Teater, Badminton, Sepak Bola, Futsal, Volly, dan Takraw), semua warga sekolah wajib menunjukkan contoh teladan yang baik seperti berpakaian yang rapi, berkarakter dalam sikap, tindakan dan perbuatan, guru dan staf menindak tegas dengan sanksi jika ada peserta didik yang melanggar disiplin atau tata tertib (terlambat tiba disekolah, berkelahi, berpakaian tidak rapi, buang sampah sembarangan, berkata kasar), serta mengarahkan dan mengirim peserta didik untuk aktif mengikuti ajang perlombaan agar terbentuk karakter berani berkompetisi (Tim Pengembang Pendidikan Budaya dan Karakter Bangsa, 2010).

Semua kegiatan yang dilakukan oleh sekolah sebagaimana di atas pada hakikatnya ingin membentuk budaya sekolah yang berkarakter melalui pembiasaan dalam kehidupan sekolah. Sebagaimana Berkowitz menyatakan bahwa "Effective character education is nota adding a programs to a school. Rather it is a transformation of the culture and life of the school". Dari pandangan tersebut dapat dipahami bahwa implementasi pendidikan karakter melalui transformasi budaya dan perikehidupan sekolah, dirasakan lebih efektif daripada mengubah kurikulum dengan menambahkan materi pendidikan karakter kedalam muatan kurikulum (Samani \& Hariyanto, 2013).

\section{SIMPULAN DAN SARAN}

\section{Kesimpulan.}

1. Bahwa penguatan pendidikan karakter melalui program pengembangan diri di Sekolah Menengah Atas (SMA) Perbatasan Entikong Kalimantan Barat dilakukan melalui kegiatan rutin, kegiatan spontan, kegiatan keteladanan dan kegiatan pengondisian. Kegiatan rutin seperti upacara bendera pada hari senin, bersalaman antara murid dengan guru di pintu gerbang sekolah atau sebelum masuk ruang kelas, mengucapkan salam ketika masuk ruang kelas, berdoa sebelum dan setelah pembelajaran, kegiatan literasi membaca selama 30 menit sebelum pembelajaran dimulai, piket membersihkan ruang kelas oleh peserta didik secara bergantian, melaksanakan ibadah (sholat dzuhur) secara berjamaah, dan setiap tahun sekolah mendukung pelaksanaan kegiatan keagamaan. Selanjutnya kegiatan spontan yang dilakukan oleh sekolah dalam rangka pengembangan karakter peserta didik yakni menindak tegas dengan sanksi jika ada peserta didik yang melanggar disiplin atau tata tertib (terlambat tiba disekolah, berkelahi, berpakaian tidak rapi, buang sampah sembarangan, berkata kasar), melakukan penggalangan dana jika terdapat salah satu warga sekolah yang tertimpa musibah, mengunjungi warga sekolah yang sakit atau adanya kematian. Kemudian kegiatan keteladanan yang dilakukan oleh sekolah yakni semua warga sekolah wajib menunjukkan contoh teladan yang baik seperti berpakaian yang rapi, berkarakter dalam sikap, tindakan dan perbuatan. Dan terakhir kegiatan pengondisian dilakukan 
1264 Penguatan Pendidikan Karakter Berbasis Sekolah Menengah Atas (SMA) Perbatasan Entikong Kalimantan Barat - Thomy Sastra Atmaja, Jagad Aditya Dewantara, Bambang Budi Utomo DOI: https://doi.org/10.31004/basicedu.v4i4.545

melalui penataan ruang kelas, ruang guru, ruang kepala sekolah, ruang perpustakaan dan seluruh ruangan di sekolah secara rapi dan bersih, lingkungan serta halaman sekolah bersih dan rapi, taman dan lingkungan sekolah yang hijau dan terawat, tersebar banyak tong sampah di lingkungan sekolah, lingkungan sekolah bersih dari sampah, serta kondisi toilet yang bersih, terawat, dan dengan jumlah yang cukup.

2. Bahwa pengembangan/penguatan pendidikan karakter di Sekolah Menengah Atas (SMA) Perbatasan Entikong Kalimantan Barat dilakukan melalui integrasi/menyisipkan nilai karakter bangsa kedalam setiap pokok bahasan dari setiap mata pelajaran. Upaya ini dilakukan oleh guru mulai dari penyusunan Rencana Pelaksanaan Pembelajaran, tahap pelaksanaan proses pembelajaran, hingga penilaian pembelajaran (aspek afektif).

3. Bahwa pengembangan/penguatan pendidikan karakter melalui budaya sekolah di Sekolah Menengah Atas (SMA) Perbatasan Entikong Kalimantan Barat dilakukan dengan cara menetapkan visi dan motto sekolah yang mengandung nilai karakter, memajang banyak bendera merah putih di sepanjang teras sekolah untuk menumbuhkan rasa nasionalisme dan patriotisme, memajang banyak kalimat motivasi dan bernilai karakter di sepanjang lingkungan sekolah, menerapkan $5 \mathrm{~S}$ yakni (senyum, salam, sapa, sopan, santun) kepada seluruh warga sekolah, menampilkan sikap saling peduli dan kasih sayang kepada seluruh warga sekolah, menetapkan tata tertib sebagai rujukan tingkah laku seluruh warga sekolah, menciptakan program unggulan sekolah (berupa setiap pagi peserta didik dikumpulkan dilapangan untuk menyanyikan lagu-lagu kebangsaan/nasionalis serta bersalaman kepada seluruh dewan guru, ada pula program unggulan berupa menyanyikan lagu kebangsaan Indonesia Raya saat memulai pembelajaran dan menyanyikan lagu nasional/kebangsaan saat akan pulang, bahkan ada pula program unggulan berupa kegiatan Pendidikan Bela Negara pada organisasi Osis dan kegiatan Masa Orientasi Sekolah (MOS) selama 3 hari yang dilatih dari Anggota TNI maupun POLRI), melaksanakan kegiatan ekstakurikuler yang dapat membentuk karakter peserta didik seperti (OSIS, Paskibra, Pramuka, PMR, Rohis, Pendalaman Iman, Silat, Karate, Taekwondo, Teater, Badminton, Sepak Bola, Futsal, Volly, dan Takraw), semua warga sekolah wajib menunjukkan contoh teladan yang baik seperti berpakaian yang rapi, berkarakter dalam sikap, tindakan dan perbuatan, guru dan staf menindak tegas dengan sanksi jika ada peserta didik yang melanggar disiplin atau tata tertib (terlambat tiba disekolah, berkelahi, berpakaian tidak rapi, buang sampah sembarangan, berkata kasar), serta mengarahkan dan mengirim peserta didik untuk aktif mengikuti ajang perlombaan agar terbentuk karakter berani berkompetisi.

4. Bahwa terdapat 4 (empat) program unggulan yang dilaksanakan oleh SMA di Perbatasan Entikong dalam rangka mengembangkan karakter peserta didik yakni: (1) Setiap pagi peserta didik sebelum masuk ruang kelas terlebih dahulu dikumpulkan dilapangan, saat kumpul 
1265 Penguatan Pendidikan Karakter Berbasis Sekolah Menengah Atas (SMA) Perbatasan Entikong Kalimantan Barat - Thomy Sastra Atmaja, Jagad Aditya Dewantara, Bambang Budi Utomo

DOI: https://doi.org/10.31004/basicedu.v4i4.545

peserta didik dituntut harus hadir tepat waktu sebagai upaya membentuk nilai disiplin, kemudian peserta didik secara bergantian diminta untuk memimpin semua temannya menyanyikan lagu-lagu kebangsaan/nasionalis. Setelah peserta didik selesai bernyanyi kepala sekolah atau guru memberikan motivasi dan pesan-pesan moral kepada peserta didik, dan kemudian peserta didik diarahkan untuk bersalaman kepada seluruh dewan guru untuk selanjutnya masuk ke ruang kelas. (2) Program setiap akan memulai pembelajaran wajib menyanyikan lagu kebangsaan Indonesia Raya dan saat akan pulang wajib menyanyikan lagu nasional/kebangsaan. (3) Kegiatan Pendidikan Bela Negara pada organisasi Osis dan kegiatan Masa Orientasi Sekolah (MOS) selama 3 hari yang dilatih dari Anggota TNI maupun POLRI.

\section{Saran}

Pelaksanaan penguatan pendidikan karakter berbasis sekolah di SMA Perbatasan Entikong telah berjalan dengan baik, namun masih ada beberapa kendala diantaranya terdapat guru dan warga sekolah yang belum memiliki komitmen untuk melaksanakan secara serius program tersebut. Untuk menyikapi hal tersebut maka kepala sekolah dapat melakukan sosialisasi dan rembuk dalam rangka penyamaan persepsi dan langkah untuk menyukseskan program tersebut.

\section{DAFTAR PUSTAKA}

Arikunto, S. (1998). Prosedur Penelitian. Jakarta: Renika Cipta.

Creswell, J. . (2010). Research Design: Pendekatan Kualitatif, Kuantitatif, dan Mixed. Yogyakarta:
PT Pustaka Pelajar.

Dewantara, J. A., Efriani, Sulistyarini, \& Prasetiyo, W. H. (2020). Optimization of Character Education Through Community Participation Around The School Environment ( Case Study in Lab School Junior High School Bandung ). Journal of Etika Demokrasi, 5(1), 53-66.

Flora, M. (2019). Kasus Pengeroyokan Audrey dari Kronologi Hingga Petisi. Diakses 30 April 2020

Online. https://www.liputan6.com/news/read/3938047/ kasus-pengeroyokan audrey-dari-kronologihingga-petisi

Ishaq, M. (2011). Pembinaan Nasionalisme Pemuda Perbatasan Melalui Program Pendidikan Luar Sekolah. Jurnal Ilmu Pendidikan, 17(6), 459468.

http://journal.um.ac.id/index.php/jip/article/vie $\mathrm{w} / 2878$

Kementerian Pendidikan dan Kebudayaan. (n.d.). Infografis Gerakan Penguatan Pendidikan Karakter. Diakses 30 April 2020 Online. https://www.kemdikbud.go.id/main/files/downl oad/.

Mardawani, \& Kurniati, A. (2017). Model Pembinaan Rasa Kebangsaan Melalui Citizenship Education Pada Masyarakat Entikong Wilayah Perbatasan IndonesiaMalaysia. Jurnal Ilmiah Pendidikan Pancasila Dan Kewarganegaraan, 2(1), 41-47. http://journal2.um.ac.id/index.php/jppk

Miles, \& Huberman. (1992). Analisis Data Kualitatif. Jakarta : Universitas Indonesia Press.

Moleong, L. J. (2007). Metode Penelitian Kualitatif. Bandung: PT. Remaja Rosdakarya.

Peraturan Presiden Republik Indonesia Nomor 87. (2017). Penguatan Pendidikan Karakter.

Prasetiyo, W. H., Kamarudin, K. R., \& Dewantara, J. A. (2019). Surabaya green and clean: Protecting urban environment through civic engagement community. Journal of Human Behavior in the Social Environment, 29(8), 997-1014. https://doi.org/10.1080/10911359.2019.164282 1 
1266 Penguatan Pendidikan Karakter Berbasis Sekolah Menengah Atas (SMA) Perbatasan Entikong Kalimantan Barat - Thomy Sastra Atmaja, Jagad Aditya Dewantara, Bambang Budi Utomo DOI: https://doi.org/10.31004/basicedu.v4i4.545

Safitri, D. (2015). Representasi Nawacita dalam 100 Hari Kabinet Kerja Jokowi-JK. In Dialog Kebijakan Publik.

Samani, M., \& Hariyanto. (2013). Konsep dan Model Pendidikan Karakter. Bandung: Remaja Rosdakarya.

Satori, J., \& Komariah, A. (2011). Metodelogi Penelitian Kualitatif. Bandung: Alfabeta.

Sugiyono. (2011). Metode Penelitian Kuantitatif, Kualitatif $R \& D$. Bandung: Alfabeta.

Suroso, A. (2018). Kekerasan Murid dan Perlindungan Guru. https://pontianak.tribunnews.com/2018/03/09/k ekerasan-murid-dan-perlindungan-guru

Tim Pendidikan Karakter. (2010). Pendidikan Karakter Di SMP. Kementerian Pendidikan Nasional Direktorat Jenderal Kementerian Pendidikan Dasar dan Menengah Direktorat Pembinaan SMP.

Tim Pengembang Pendidikan Budaya dan Karakter Bangsa. (2010). Penguatan Metodelogi Pembelajaran Berdasarkan Nilai-Nilai Budaya Untuk Membentuk Daya Saing dan Karakter Bangsa. Pusat Kurikulum Badan Penelitian dan Pengembangan Kementerian Pendidikan dan Kebudayaan.

Tim Penguatan Pendidikan Karakter. (2012). Konsep dan Pedoman Penguatan Pendidikan Karakter Tingkat Sekolah Dasar dan Sekolah Menengah Pertama. Kementerian Pendidikan dan Kebudayaan.

Tim Penguatan Pendidikan Karakter. (2017). Konsep dan Pedoman Penguatan Pendidikan Karakter. Pusat Analisis dan Sinkronisasi, Kementerian Pendidikan dan Kebudayaan.

Yustiani. (2018). Nationalism Through School Education For Senior High School Students In Border Area Of West Kalimantan Pendahuluan. Jurnal SMaRT Studi Masyarakat, Religi Dan Tradisi, 04(01), 111-124. 